\title{
Solarização e cobertura morta no solo sobre a infestação de plantas daninhas no feijão-caupi (Vigna unguiculata)
}

\author{
Solarization and soil mulching on weed infestation in cowpea (Vigna unguiculata) \\ Sebastião de Oliveira Maia Júnior ${ }^{1 *}$, Jailma Ribeiro de Andrade ${ }^{2}$, Luciene Ribeiro de Andrade ${ }^{2}$, \\ Claudiana Moura dos Santos ${ }^{2}$, Lennon Kledson dos Santos Silva² ${ }^{2}$, Aldair de Souza Medeiros ${ }^{2}$ e Lígia \\ Sampaio Reis ${ }^{2}$
}

${ }^{1}$ Universidade Federal de Campina Grande, Campina Grande, PB, Brasil. *Autor para correspondência: juniormaiagrari@hotmail.com.
${ }^{2}$ Universidade Federal de Alagoas, Maceió, AL, Brasil.

Submissão:02/01/2019 / Aceite: 01/07/2019

\begin{abstract}
RESUMO
A infestação de plantas daninhas está entre os problemas de maior interferência na agricultura, e por isso tem despertado a utilização de técnicas de manejo, como o uso de solarização e coberturas vegetais sobre o solo, que podem atenuar essa problemática. Dessa forma, objetivou-se com este trabalho avaliar os manejos de solarização e cobertura morta do solo sobre a infestação de plantas daninhas no cultivo do feijão-caupi. O experimento foi realizado em casa de vegetação sob delineamento inteiramente casualizado com oito tratamentos, como sendo: solarização do solo (com e sem) e três coberturas mortas (mamona, crotalária e vegetação espontânea + ausência de cobertura) com quatro repetições. A pesquisa foi conduzida em vasos com capacidade de $11 \mathrm{dm}^{3}$, preenchidos com oito $\mathrm{kg}$ de solo, e a semeadura realizada diretamente nos vasos. Aos 80 dias após a semeadura, foram determinados o número e a massa seca total de plantas daninhas em cada unidade experimental. Nesse período também foram avaliadas as características de crescimento e rendimento do feijão-caupi. O número e massa seca total de plantas daninhas foram maiores no solo sem cobertura, independente da solarização, sendo a massa seca total maior na ausência da solarização. Essa infestação de plantas daninhas reduziu o comprimento do ramo principal, número de folhas, número e comprimento de vagens, produção de massa seca e quantidade de água na parte aérea do feijão-caupi, enquanto aumentou a massa seca radicular. A solarização quando isolada não suprime totalmente a incidência de plantas daninhas, mas reduz o desenvolvimento destas. Por outro lado, a cobertura do solo, independente do tipo e da solarização, reduz a incidência de plantas daninhas favorecendo o crescimento, rendimento e produção de massa seca na parte aérea do feijão-caupi.
\end{abstract}

PALAVRAS-CHAVE: Vigna unguiculata, plantas invasoras, rendimento.

\begin{abstract}
Weed infestation is among the problems of greater interference in agriculture, and therefore has awakened the use of management techniques, as the use of solarization and mulching on the ground, that can mitigate this problem. Thus, was objectified with this work to evaluate the management of solarization and soil mulching on weed infestation in cowpea. The experiment was carried in greenhouse under a completely randomized design with eight treatments, such as: soil solarization (with and without) and three dead cover crops (castor bean, crotalaria and spontaneous vegetation + with four replications. The research was conducted in pots with a capacity of $11 \mathrm{dm}^{3}$, filled with eight $\mathrm{kg}$ of soil, and the sowing was carried out directly in the pots. At 80 days after sowing, the number and total dry mass of weeds in each experimental unit were determined. During this period, the growth and yield characteristics of cowpea were also evaluated. The number and total dry mass of weeds were higher in the uncovered soil, independent of solarization, and the dry mass was higher in the absence of solarization. This weed infestation reduced the length of the main branch, number of leaves, number and length of pods, production of dry mass and amount of water in the aerial part of the cowpea, while increasing the root dry mass. Solarization, when isolated, does not totally suppress the incidence of weeds, but reduces their development. On the other hand, soil cover, independent of type and solarization, reduces the incidence of weeds favoring growth, yield and dry matter production in the aerial part of the cowpea.
\end{abstract}

KEYWORDS: Vigna unguiculata, invasive plants, yield. 


\section{INTRODUÇÃO}

No Brasil, a cultura do feijoeiro tem importante destaque na agricultura nacional, onde os grãos representam uma importante fonte de proteína e minerais na dieta da população, além de possuir notória importância socioeconômica (MAGALHÃES et al. 2017). A produção brasileira em 2017 foi de 3.033.017 toneladas, sendo o estado do Paraná o maior produtor (691.867 toneladas), seguido por Minas Gerais (498.441 toneladas) e Mato Grosso (352.422 toneladas), enquanto que, a produção dessa leguminosa no

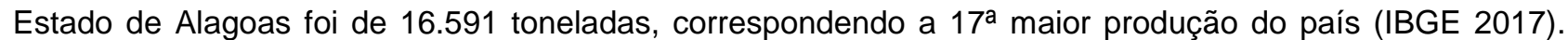
Dentre as espécies de feijão, a variedade feijão-caupi (Vigna unguiculata) por ser de origem africana, é bastante difundida nas diversas regiões tropicais do planeta, e uma das culturas mais produzidas na região Nordeste do Brasil (BEZERRA et al. 2014).

A infestação de plantas daninhas está entre os problemas de maior interferência na agricultura, causando perdas significativas de até $67 \%$ na produtividade das culturas como no feijão-caupi, devido à alelopatia, competição por luz, água e nutrientes (SALGADO et al. 2007, PESSÔA et al. 2017). Dessa maneira, diversas estratégias de manejo têm sido adotadas com o propósito de minimizar ou erradicar a infestação de plantas daninhas, como a solarização do solo e a cobertura morta que vêm sendo aplicadas em diferentes culturas, inclusive no feijão-caupi que, assim como outras espécies da família Fabaceae, é concorrente pobre com plantas daninhas por causa da baixa estatura e fechamento lento da copa, o que reduz significativamente seu crescimento e rendimento.

Nesse contexto, uma alternativa viável para o controle de plantas daninhas durante o cultivo do feijoeiro é a solarização do solo. Esse é um método físico de desinfestação, que consiste na cobertura do solo úmido com filme de polietileno durante a época mais quente do ano (SANTOS et al. 2014), utilizado para aumentar a temperatura do solo e consequentemente, erradicar patógeno, nematoides e sementes de plantas daninhas (KATAN 1981, BAPTISTA et al. 2006). Esse método é eficiente e de fácil execução, além de ser ambientalmente seguro, tornando-se aceitável para a comunidade agrícola, já que não necessita de procedimentos especiais de precaução para ser realizado (KHAN et al. 2012, OSIPITAN 2017). Em cultivo de amendoim (Arachis hypogaea L.) a solarização do solo com polietileno transparente por 45 dias reduziu significativamente o número e a massa seca das plantas daninhas, até o momento da colheita (SOUMYA et al. 2004). Já em couve-flor (Brassica oleracea var. botrytis), a solarização realizada antes do plantio melhorou o rendimento da cultura por diminuir a densidade e a massa seca de plantas daninhas, além de aumentar os níveis de nitrogênio e matéria orgânica no solo (KHAN et al. 2012).

Além da solarização, a cobertura morta também tem sido apontada como uma técnica bastante eficiente, pois a camada sobreposta ao solo inibe a germinação de plantas daninhas, devido à redução na interceptação de luz e oscilação na temperatura do solo, o que impede a quebra de dormência das sementes (MARTINS et al. 2016). A decomposição de algumas espécies de coberturas mortas pode liberar aleloquímicos, os quais dificultam a germinação e desenvolvimento das plantas daninhas (HIRATA et al. 2009). Outros efeitos positivos da cobertura morta do solo estão relacionados à proteção contra a erosão e redução da taxa de evaporação de água do solo (TEÓFILO et al. 2012, FERREIRA et al. 2015). Além disso, a cobertura pode ser de diferentes origens, apesar da eficiência variar a depender do tipo utilizado (MESCHEDE et al. 2007, MONQUERO et al. 2009). De acordo com MESCHEDE et al. (2007) palhadas de sorgo (Sorghum bicolor L. Moench), milheto (Pennisetum glaucum (L.) R. Brown) e crotalária (Crotalaria juncea L.) apresentaram boa supressão das plantas daninhas, promovendo maior cobertura do solo e maior captação de luz pelo dossel. MARTINS et al. (2016) constataram que a cobertura morta de aveia-preta (Avena strigosa Schreber) e nabo-forrageiro (Raphanus sativus L.) proporcionaram as menores densidades de plantas e acúmulo de matéria seca de plantas daninhas na cultura do milho. Similarmente, ALMEIDA et al. (1996) observaram que a cobertura de milheto (Pennisetum glaucum (L.) R. Brown) e crotalária (Crotalaria juncea L.) controlaram a incidência de plantas daninhas na cultura do milho.

Diante do exposto, objetivou-se com esse trabalho avaliar os efeitos da solarização e cobertura morta do solo sobre o controle de plantas daninhas, bem como o crescimento e rendimento do feijão-caupi.

\section{MATERIAL E MÉTODOS}

O experimento foi instalado em casa de vegetação entre outubro e dezembro de 2016 na unidade experimental do Centro de Ciências Agrárias da Universidade Federal de Alagoas, UFAL, município de Rio Largo, AL ( $09^{\circ} 28^{\prime} \mathrm{S}, 35^{\circ} 49^{\prime} \mathrm{W}$ e $127 \mathrm{~m}$ de altitude), cujo clima é caracterizado como quente úmido (MAGALHÃES et al. 2017).

Foram utilizados vasos com capacidade para $11 \mathrm{dm}^{3}$, preenchidos com oito $\mathrm{kg}$ de solo classificado como Latossolo Amarelo (SANTOS et al. 2013). As características físicas e químicas do solo utilizado no 
experimento encontram-se na Tabela 1. O solo foi previamente destorroado, peneirado e solarizado. A solarização foi realizada com filme de polietileno preto de $50 \mu \mathrm{m}$, sendo o solo irrigado próximo à capacidade de campo, totalmente coberto pelo plástico numa camada de $10 \mathrm{~cm}$ de altura e exposto ao sol durante 30 dias; nessa metodologia a temperatura no solo varia entre 40 e 52 으 (KATAN 1981).

Tabela 1. Caracterização físico-química do solo utilizado no experimento.

Table 1. Physical-chemical characterization of the soil used in the experiment.

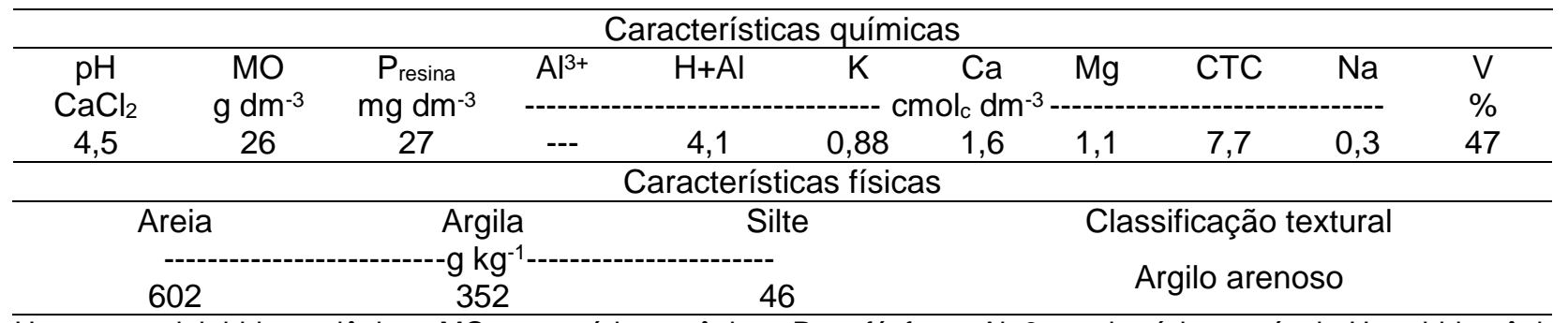

$\mathrm{pH}=$ potencial hidrogeniônico, $\mathrm{MO}=$ matéria orgânica, $\mathrm{P}=$ fósforo, $\mathrm{Al}+3$ = alumínio trocável, $\mathrm{H}=$ hidrogênio, $\mathrm{Ca}=$ cálcio, $\mathrm{Mg}$ = magnésio, $\mathrm{CTC}=$ capacidade de troca catiônica, $\mathrm{Na}=$ sódio, $\mathrm{V}=$ saturação por bases.

Em associação com a solarização foram testados três tipos de coberturas mortas sobre o solo: mamona (Ricinus communis L.), crotalária (Crotalaria ochroleuca) e vegetação espontânea, as quais foram obtidas em áreas não cultivadas.

O delineamento experimental utilizado foi o inteiramente casualizado, com oito tratamentos e quatro repetições, totalizando 32 parcelas, cada uma correspondente a uma planta de feijão-caupi por vaso. Os tratamentos foram designados como: T1 (solo solarizado com cobertura morta de mamona), T2 (solo solarizado com cobertura morta de crotalária), T3 (solo solarizado com cobertura morta de vegetação espontânea), T4 (solo solarizado sem cobertura morta), T5 (solo não solarizado com cobertura morta de mamona), T6 (solo não solarizado com cobertura morta de crotalária), T7 (solo não solarizado com cobertura morta de vegetação espontânea) e T8 (controle: solo não solarizado e sem cobertura morta).

A semeadura do feijão-caupi foi realizada diretamente nos vasos contendo o solo conforme o tratamento (solarizado e não solarizado), nos quais foram colocadas três sementes em cada. Aos sete dias após a semeadura (DAS) foi realizado o desbaste deixando uma planta por vaso. Em seguida, adicionou-se $100 \mathrm{~g}$ de cobertura morta por vaso, o suficiente para cada tipo de cobertura cobrir todo o solo no vaso; o solo foi irrigado próximo à capacidade de campo com turno de rega de três dias.

Em estudos similares com a cultura do feijão-caupi e o mesmo tipo de solo foi observada a ocorrência de 14 espécies diferentes de plantas daninhas, sendo as mais frequentes Cyperus rotundus, Brachiaria decumbens e Amaranthus deflexus (MAIA JÚNIOR et al. 2018).

Aos 80 DAS foi realizada a avaliação das espécies daninhas infestantes em cada unidade experimental, sendo a amostragem feita por meio de coleta do material, obtida pelo método de quadrado inventário de 0,25 $\mathrm{m}^{2}$ jogado ao acaso, uma única vez em cada parcela (BRAUN-BLANQUET 1979). Na ocasião, as plantas daninhas foram coletadas, sendo determinados o número (NPD) e a massa seca total de plantas daninhas (MSTPD).

Foram avaliadas também as características de crescimento e rendimento do feijão-caupi: comprimento do ramo principal (CRP), número de folhas (NF), número de vagens por planta (NVP), comprimento de vagens (CV), número de grãos por vagem (NGV), massa fresca (MFPA) e seca da parte aérea (MSPA), massa seca da raiz (MSR) e quantidade de água na parte aérea (QAPA).

A massa seca, tanto das plantas daninhas quanto do feijão-caupi, foi obtida após a secagem das mesmas em estufa de circulação de ar a $65^{\circ} \mathrm{C}$ durante 48 horas. Em seguida, o material foi pesado em balança de precisão $(0,001 \mathrm{~g})$.

A quantidade de água na parte aérea do feijão-caupi foi obtida pela razão entre a massa fresca e seca da parte aérea das plantas, conforme metodologia apresentada por BORGES et al. (2014).

Os dados foram submetidos à análise de variância pelo teste $F(p<0,05)$ e quando significativos, foram comparadas pelo teste de agrupamento de médias Scott-Knott, utilizando-se o programa estatístico Sisvar 5.6. A correlação de Pearson ( $r$ ) foi utilizada para verificar a relação entre a infestação de plantas daninhas e o crescimento e rendimento do feijão-caupi.

\section{RESULTADOS}

O número de plantas daninhas (NPD) foi maior em T4 e T8, em comparação aos demais tratamentos, 
os quais apresentaram valores, cerca de 90\% superiores ao T2, que apresentou a menor média do NPD. De forma semelhante, a massa seca total de plantas daninhas (MSTPD) foi superior no T8, seguido de T4, e com menor massa nos demais tratamentos, onde os aumentos foram de até 97,5\%, quando comparado ao tratamento (T3) com menor MSTPD (Tabela 2).

Tabela 2. Número e massa seca total de plantas daninhas em feijão-caupi cultivado sob manejos de solarização e cobertura morta no solo.

Table 2. Number and total dry mass of weeds in cowpea cultivated under solarization and soil mulching.

\begin{tabular}{ccc}
\hline Tratamentos & $\begin{array}{c}\text { Número de plantas daninhas } \\
\left(\mathrm{n} \mathrm{vaso}^{-1}\right)\end{array}$ & $\begin{array}{c}\text { Massa seca total de plantas } \\
\text { daninhas } \\
\left(\mathrm{g} \mathrm{vaso}^{-1}\right)\end{array}$ \\
\hline T1 & $3,25 \mathrm{~b}$ & $1,36 \mathrm{c}$ \\
T2 & $2,25 \mathrm{~b}$ & $2,28 \mathrm{c}$ \\
T3 & $3,00 \mathrm{~b}$ & $0,56 \mathrm{c}$ \\
T4 & $25,50 \mathrm{a}$ & $12,86 \mathrm{~b}$ \\
T5 & $4,50 \mathrm{~b}$ & $4,12 \mathrm{c}$ \\
T6 & $3,75 \mathrm{~b}$ & $2,46 \mathrm{c}$ \\
T7 & $4,50 \mathrm{~b}$ & $2,66 \mathrm{c}$ \\
T8 & $23,25 \mathrm{a}$ & $22,26 \mathrm{a}$ \\
\hline CV & 38,6 & 37,4 \\
\hline
\end{tabular}

$\overline{\mathrm{CV}}(\%)=$ coeficiente de variação. Médias seguidas pelas mesmas letras na coluna não diferem entre si pelo critério de agrupamento Scott-Knott $(p<0.05)$.

O NPD se correlacionou negativamente com o comprimento do ramo principal (CRP), número de vagens por planta (NVP), comprimento de vagens (CV), massa fresca (MFPA), massa seca da parte aérea (MSPA) e quantidade de água na parte aérea (QAPA) do feijão-caupi, com destaque para o número de folhas (NF) (Figura 1A-G), enquanto que, com a massa seca da raiz (MSR) a correlação foi positiva (Figura $1 \mathrm{H})$.
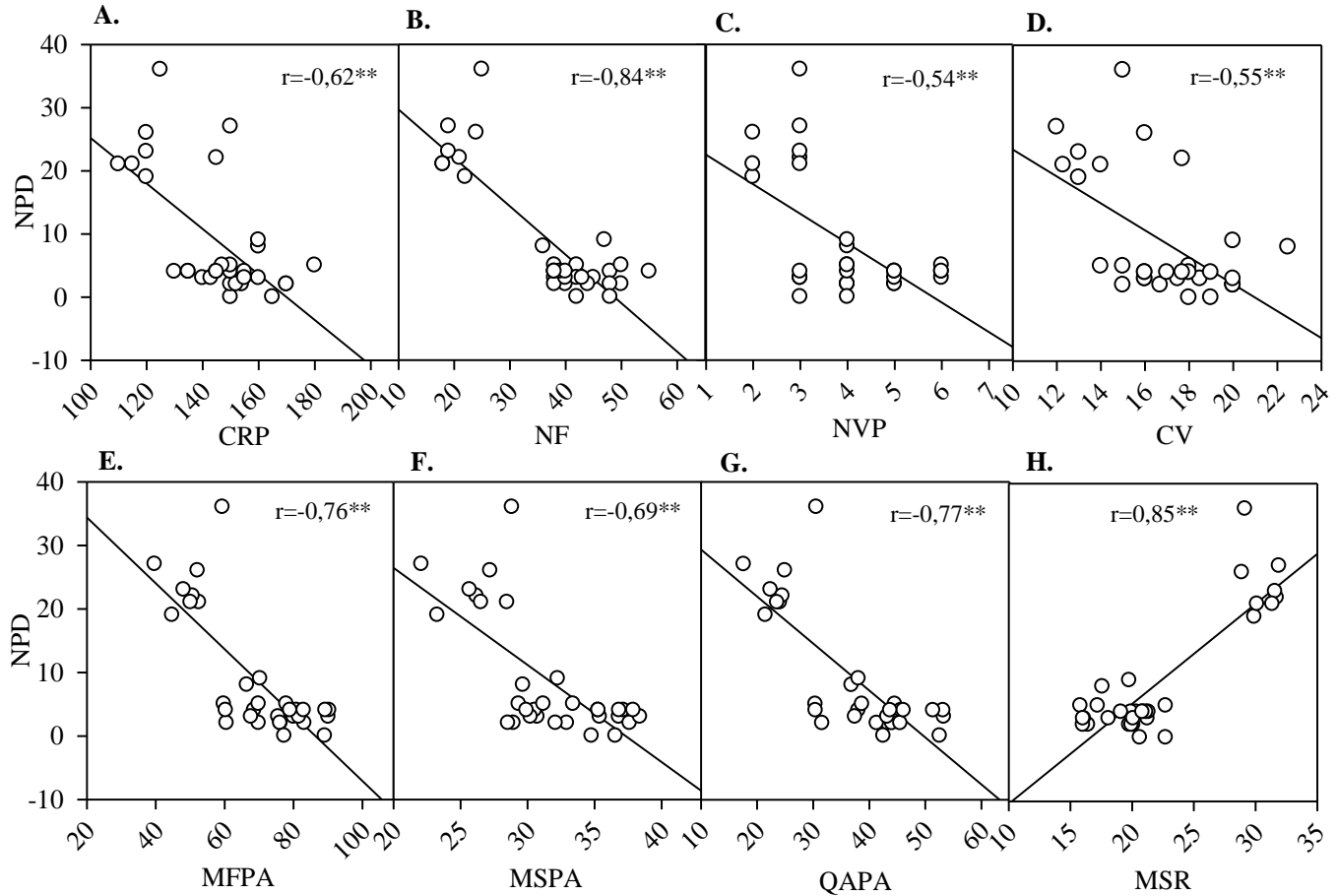

Figura 1. Correlação entre o número de plantas daninhas e as características de crescimento e rendimento do feijão-caupi. CRP: comprimento do ramo principal, NF: número de folhas, NVP: número de vagens por planta, CV: comprimento de vagens, MFPA: massa fresca da parte aérea, MSPA: massa seca da parte aérea, QAPA: quantidade de água na parte aérea do feijão-caupi e MSR: massa seca da raiz.

Figure 1. Correlation between the number of weeds and the growth and yield characteristics of cowpea. CRP: main branch length, NF: number of leaves, NVP: number of pods per plant, CV: pod length, MFPA: fresh shoot mass, MSPA: dry mass of the aerial part, QAPA: amount of water in the aerial part of the cowpea and MSR: root dry mass. 
Da mesma forma que o NPD, a MSTPD também se correlacionou negativamente com as características de crescimento e rendimento do feijão-caupi, e positiva com a MSR (Figura 2). Além disso, observou-se que as correlações da MSTPD foram mais fortes que do NPD.
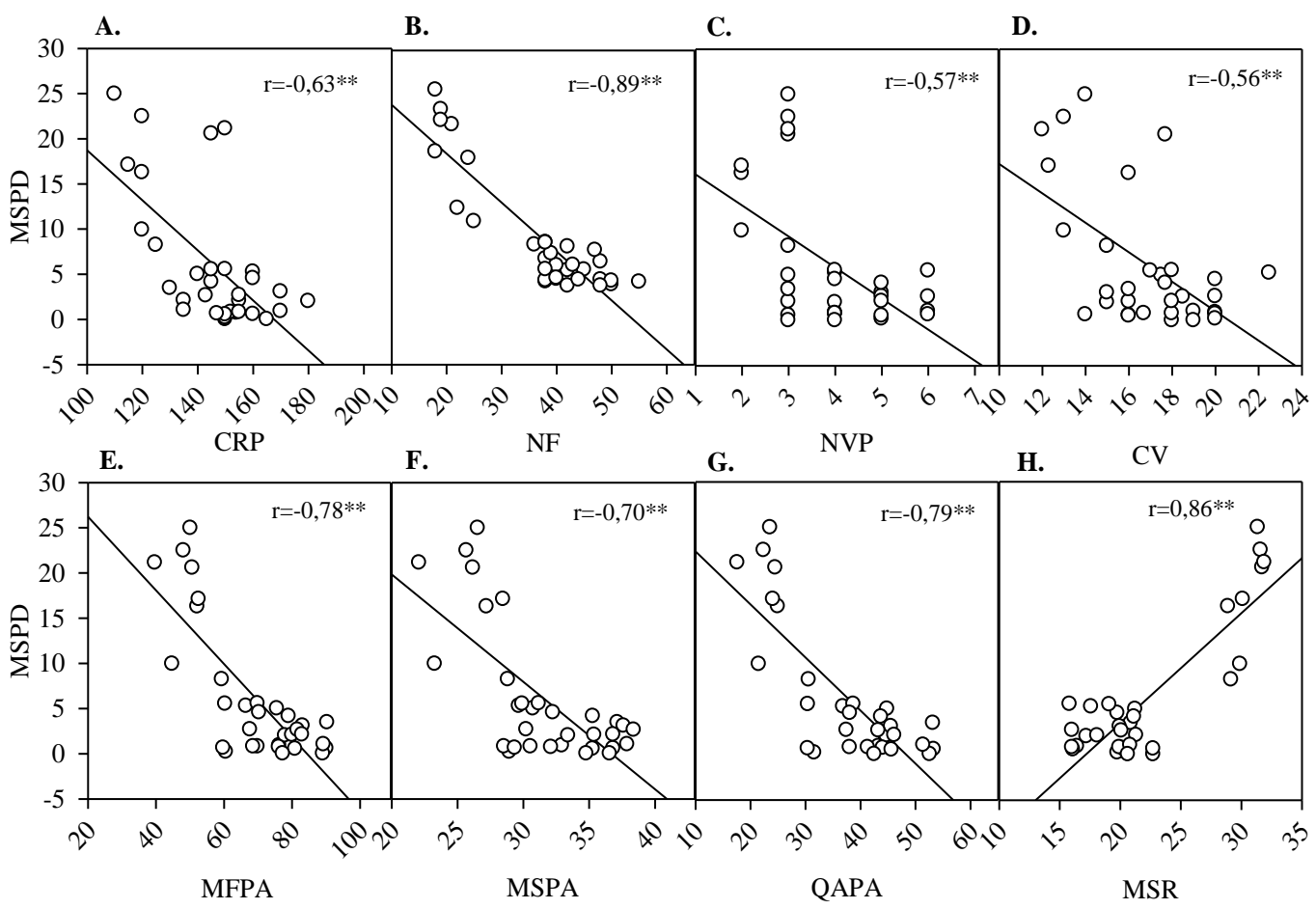

Figura 2. Correlação entre a massa seca de plantas daninhas e as características de crescimento e rendimento do feijão-caupi. CRP: comprimento do ramo principal, NF: número de folhas, NVP: número de vagens por planta, $\mathrm{CV}$ : comprimento de vagens, MFPA: massa fresca da parte aérea, MSPA: massa seca da parte aérea, QAPA: quantidade de água na parte aérea do feijão-caupi e MSR: massa seca da raiz.

Figure 2. Correlation between the dry mass of weeds and the growth and yield characteristics of cowpea. CRP: main branch length, NF: number of leaves, NVP: number of pods per plant, CV: pod length, MFPA: fresh shoot mass, MSPA: dry mass of aerial part, QAPA: amount of water in the aerial part of the cowpea and MSR: root dry mass.

O CRP, NF e NVP tiveram menor desempenho em T4 e T8, seguidos dos demais tratamentos, destacando-se T1, T3 e T7 com maiores valores, respectivamente, enquanto T2 e T6 representaram a cobertura com menor efeito sobre essas variáveis (Tabela 3). Observou-se também que o CV foi menor em T4 e T8, e maior nos demais tratamentos. Enquanto isso, o NGV não variou entre os tratamentos avaliados.

Tabela 3. Comprimento do ramo principal (CRP), número de folhas (NF), número de vagens por planta (NVP), comprimento de vagem (CV) e número de grãos por vagem (NGV) em feijão-caupi cultivado sob manejos de solarização e cobertura morta no solo.

Table 3. Length of main branch (CRP), number of leaves (NF), number of pods per plant (NVP), pod length (CV) and number seeds per pod (NGV) in cowpea cultivated under solarization and soil mulching.

\begin{tabular}{|c|c|c|c|c|c|}
\hline Tratamentos & $\begin{array}{c}\text { CRP } \\
\left(\mathrm{cm}_{\text {planta-1 }}\right)\end{array}$ & $\begin{array}{c}\text { NF } \\
\left(\text { n planta-1) }^{-1}\right)\end{array}$ & $\begin{array}{c}\text { NVP } \\
\left(\text { n planta }^{-1}\right)\end{array}$ & $\begin{array}{c}\text { CV } \\
\left(\mathrm{cm} \text { vagem }{ }^{-1}\right)\end{array}$ & $\begin{array}{c}\text { NGV } \\
\left(\text { n vagem }^{-1}\right)\end{array}$ \\
\hline T1 & $166,25 \mathrm{a}$ & $41,25 \mathrm{~b}$ & $3,50 \mathrm{~b}$ & $16,75 \mathrm{a}$ & $8,12 \mathrm{a}$ \\
\hline $\mathrm{T} 2$ & $143,50 \mathrm{~b}$ & $40,00 \mathrm{~b}$ & $3,25 b$ & $17,87 \mathrm{a}$ & $11,50 \mathrm{a}$ \\
\hline T3 & $151,75 a$ & $49,25 \mathrm{a}$ & $4,50 a$ & $17,67 \mathrm{a}$ & $9,45 \mathrm{a}$ \\
\hline $\mathrm{T} 4$ & $120,00 \mathrm{c}$ & $22,25 \mathrm{c}$ & $2,25 \mathrm{c}$ & $14,07 \mathrm{~b}$ & $11,75 \mathrm{a}$ \\
\hline T5 & $158,75 a$ & $41,25 \mathrm{~b}$ & $4,50 a$ & $18,87 \mathrm{a}$ & $10,55 \mathrm{a}$ \\
\hline T6 & $139,50 \mathrm{~b}$ & $39,25 \mathrm{~b}$ & $5,50 a$ & $18,30 \mathrm{a}$ & $12,25 \mathrm{a}$ \\
\hline $\mathrm{T} 7$ & $154,25 \mathrm{a}$ & $45,75 a$ & $5,00 \mathrm{a}$ & $17,50 \mathrm{a}$ & $9,93 \mathrm{a}$ \\
\hline T8 & $131,25 \mathrm{c}$ & $19,25 \mathrm{c}$ & $3,00 \mathrm{~b}$ & $14,17 \mathrm{~b}$ & $8,48 a$ \\
\hline CV & 6,9 & 9,6 & 15,9 & 12,7 & 19,7 \\
\hline
\end{tabular}

$\overline{\mathrm{CV}}(\%)=$ coeficiente de variação. Médias seguidas pelas mesmas letras na coluna não diferem entre si pelo critério de agrupamento Scott-Knott $(p<0.05)$. 
A MFPA, MSPA e QAPA tiveram comportamento semelhante, sendo superior em T1, T2 e T6, seguidos de T3, T5 e T7, e com menores valores nos tratamentos com solo sem cobertura, independente da solarização, T4 e T8 (Tabela 4). Já a massa seca da raiz foi maior no tratamento com ausência de solarização e cobertura morta (T8), seguido do tratamento sem solarização com cobertura (T4), enquanto menor massa da raiz foi observada em T1, T3 e T5 (Tabela 4).

Tabela 4. Massa fresca (MFPA) e seca da parte aérea (MSPA), massa seca da raiz (MSR) e quantidade de água na parte aérea (QAPA) em feijão-caupi cultivado sob manejos de solarização e cobertura morta no solo.

Table 4. Fresh matter (MFPA) and dry shoot matter (MSPA), dry root matter (MSR) and quantity of water in the aerial part (QAPA) in cowpea cultivated under solarization and soil mulching.

\begin{tabular}{|c|c|c|c|c|}
\hline Tratamentos & MFPA & MSPA & QAPA & MSR \\
\hline T1 & $81,16 \mathrm{a}$ & $34,65 \mathrm{a}$ & $46,50 \mathrm{a}$ & $16,98 d$ \\
\hline T2 & $82,86 \mathrm{a}$ & $34,15 a$ & $48,70 \mathrm{a}$ & $21,25 \mathrm{c}$ \\
\hline T3 & $70,05 \mathrm{~b}$ & $30,84 \mathrm{~b}$ & $39,20 \mathrm{~b}$ & $19,03 d$ \\
\hline T4 & $52,29 \mathrm{c}$ & $26,96 \mathrm{c}$ & $25,32 \mathrm{c}$ & $29,54 \mathrm{~b}$ \\
\hline T5 & $71,86 \mathrm{~b}$ & $32,19 \mathrm{~b}$ & $39,67 \mathrm{~b}$ & $17,37 \mathrm{~d}$ \\
\hline T6 & $83,28 \mathrm{a}$ & $37,11 \mathrm{a}$ & $46,17 \mathrm{a}$ & $20,86 \mathrm{c}$ \\
\hline T7 & $67,00 \mathrm{~b}$ & $31,59 \mathrm{~b}$ & $35,41 \mathrm{~b}$ & $20,57 \mathrm{c}$ \\
\hline T8 & $47,21 \mathrm{c}$ & $25,14 \mathrm{c}$ & $22,07 \mathrm{c}$ & $31,66 \mathrm{a}$ \\
\hline $\mathrm{CV}$ & 9,9 & 8,3 & 12,1 & 5,7 \\
\hline
\end{tabular}

$\overline{\mathrm{CV}}(\%)=$ coeficiente de variação. Médias seguidas pelas mesmas letras na coluna não diferem entre si pelo critério de agrupamento Scott-Knott $(\mathrm{p}<0.05)$.

\section{DISCUSSÃO}

Os manejos da solarização e cobertura do solo mostraram-se eficientes para o cultivo do feijão-caupi (Vigna unguiculata), diminuindo a incidência de plantas daninhas, e como consequência, melhorando as características de crescimento e rendimento do feijão-caupi, como constatado pelas correlações em que o aumento no número e massa seca de plantas daninhas reduziu todas as características avaliadas da cultura, exceto a massa da raiz. No entanto, foi observado que a solarização, quando isolada, conseguiu reduzir apenas a massa seca das plantas daninhas em relação à solarização associada à cobertura morta, indicando que as plantas daninhas incidentes no tratamento sem solarização se desenvolveram mais que no solo solarizado, já que a incidência foi semelhante entre ambos os tratamentos. Esse comportamento está relacionado ao efeito estufa provocado pela cobertura do solo com filme de polietileno durante a solarização, o que eleva a temperatura do solo e, consequentemente, afeta a germinação das sementes e o desenvolvimento das plântulas de espécies daninhas (BAPTISTA et al. 2006, SANTOS et al. 2014).

Dessa maneira, o efeito desses manejos em conjunto refletiu no maior crescimento das plantas de feijão com maior emissão de folhas, bem como maior número e comprimento de vagens. Esses efeitos positivos na cultura do feijoeiro são resultados dos manejos realizados no solo, que reduziram a infestação das plantas daninhas. Quando a lavoura é cultivada livre de plantas daninhas, as plantas melhoram tanto 0 crescimento quanto o rendimento produtivo (CABRAL et al. 2013, SIDDIQUI et al. 2018).

Alguns estudos também verificaram que a solarização foi eficiente para os cultivos agrícolas de alface (Lactuca sativa L.) (CANDIDO et al. 2011), couve-flor (Brassica oleracea var. botrytis) (KHAN et al. 2012) e tomate (Solanum lycopersicum) (BAPTISTA et al. 2006) em que o rendimento dessas culturas foi maior com o solo solarizado, devido maior controle sobre a ocorrência de plantas daninhas e sobrevivência de fitopatógenos de solo, o que favorece o desenvolvimento das plantas (SANTOS et al. 2014). No entanto, como nesse estudo a solarização isolada não se sobressaiu em relação ao solo não solarizado para o cultivo do feijoeiro, pode-se sugerir que o período de 30 dias de solarização foi curto. KHAN et al. (2012) estudando solarização em couve-flor observaram que a eficiência desse tipo de manejo aumentou até 60 dias.

Observou-se nesse estudo que a massa seca da raiz foi maior nas plantas do solo não solarizado sem cobertura, seguido do solarizado também sem cobertura. Tal fato, possivelmente ocorreu devido à maior infestação de plantas daninhas nesses tratamentos, o que levou a maior competição por água, como constatado pela menor quantidade de água na parte aérea das plantas de feijão-caupi. Assim, como o turno de rega era realizado a cada três dias, nos tratamentos com ou sem solarização e sem cobertura em que 
tiveram maior incidência de plantas daninhas, essas competiram por água com o feijoeiro.

Quando há alta densidade populacional de plantas daninhas e não se faz manejo de controle, ocorre um maior consumo de água em competição com a cultura de interesse (TEÓFILO et al. 2012, OLIVEIRA et al. 2018), o que foi verificado nesse estudo pelas correlações do número e massa seca total de plantas daninhas com a quantidade de água nas plantas de feijão-caupi. Além disso, os solos sem cobertura tiveram maior exposição e consequente evaporação, o que induziu o crescimento radicular pela busca de água. Em condições de limitação de água no solo, as plantas de feijoeiro aprofundam o sistema radicular como estratégia de escape a essa adversidade ambiental, alocando a maioria dos fotoassimilados nas folhas para manter a atividade metabólica e superar a perda de massa seca na parte aérea (OLIVEIRA et al. 2018). A cobertura morta inibe a germinação das sementes de plantas daninhas devido à redução na interceptação de luz e mudança na temperatura do solo (MARTINS et al. 2006). Além disso, algumas coberturas mortas liberam aleloquímicos, que afetam a germinação e o desenvolvimento das plantas daninhas (HIRATA et al. 2009)

Por outro lado, observou-se que a cobertura do solo independente da solarização inibiu a infestação de plantas daninhas, favorecendo o crescimento do feijão-caupi. Resultados semelhantes foram encontrados por FLÔRES et al. (2017), os quais observaram que o feijão comum (Phaseolus vulgaris L.) crescendo em palha de braquiária tiveram maior rendimento de grãos. Da mesma maneira, YEGANEHPOOR et al. (2015) observaram que plantas de cobertura inibiram a germinação e desenvolvimento de plantas daninhas no cultivo do milho (Zea mays), o que proporcionou incremento na produtividade da cultura. Esse efeito, provavelmente também ocorreu com o feijão-caupi, como visualizado pelas correlações avaliadas nesse estudo entre a incidência de plantas daninhas e as características do feijoeiro.

Contudo, observaram-se pequenas variações entre os tipos de cobertura morta e as características das plantas de feijão, como a crotalária e mamona que se alteraram entre o crescimento, rendimento e produção de massa seca do feijoeiro. Resultados semelhantes também foram encontrados com a cultura do feijão por FORTE et al. (2018), que ao avaliarem diferentes tipos de cobertura do solo observaram que aveia-preta (Avena strigosa Schreber) + nabo-forrageiro (Raphanus sativus L.) se sobressaiu ao nabo sozinho para o número de vagens por planta, enquanto ocorreu o contrário para o rendimento de grãos. De acordo com os autores, esse comportamento pode ser devido à disponibilidade de nutrientes ofertada por cada cobertura, especificamente o nitrogênio, que varia durante o ciclo da cultura.

Apesar das diferenças entre os tipos de cobertura, todas influenciaram positivamente no controle das plantas daninhas e nas características de crescimento e rendimento do feijão. Isso ocorre porque a cobertura do solo com palha além do aporte de nutrientes, tende a promover maior atividade microbiana, ao longo do tempo (ZIECH et al. 2014), e melhorar a qualidade física do solo com a retenção da umidade (FERREIRA et al. 2015). De acordo com esses autores, o uso da cobertura morta melhorou o rendimento da mamoneira cultivada sob condições de déficit hídrico, possivelmente pela manutenção da umidade do solo. Essa condição parece ter ocorrido nesse estudo, em que os tratamentos com cobertura do solo proporcionaram maior quantidade de água na parte aérea das plantas de feijão, intimamente relacionada com a produção de massa seca.

\section{CONCLUSÃO}

A solarização de 30 dias com filme de polietileno preto, realizada isoladamente, não suprime totalmente a incidência de plantas daninhas, mas reduz o desenvolvimento destas na cultura do feijãocaupi. Já a cobertura do solo, independente do tipo e da solarização, reduz a incidência de plantas daninhas favorecendo no crescimento, rendimento e produção de massa seca na parte aérea do feijão-caupi.

\section{REFERÊNCIAS}

ALMEIDA RA et al. 1996. Efeitos de diversas espécies de cobertura morta sobre o controle de plantas daninhas da cultura do milho (Zea mays). Pesquisa Agropecuária Tropical 26: 71-78.

BAPTISTA MJ et al. 2006. Solarização do solo e biofumigação no cultivo protegido de tomate. Horticultura Brasileira 24 : 47-52.

BEZERRA AAC et al. 2014. Morfofisiologia e produção de feijão-caupi, cultivar BRS Novaera, em função da densidade de plantas. Revista Caatinga 27: 135-141.

BORGES LS et al. 2014. Índices morfo-fisiológicos e produtividade de cultivares de jambu influenciadas pela adubação orgânica e mineral. Bioscience Journal 30: 1768-1778.

BRAUN-BLANQUET J. 1979. Fitossociologia: bases para el estudio de las comunidades vegetales. Madrid: H. Blume. $820 \mathrm{p}$. 
CABRAL PHR et al. 2013. Interferência de plantas daninhas na cultura do sorgo cultivado em safrinha. Pesquisa Agropecuária Tropical 43: 308-314.

CANDIDO $\mathrm{V}$ et al. 2011. Weed control and yield response of soil solarization with different plastic films in lettuce. Scientia Horticulturae 130: 491-497.

FERREIRA NM et al. 2015. Crescimento e produção da mamoneira BRS Paraguaçu sob irrigação, cobertura do solo e adubação orgânica. Revista Brasileira de Engenharia Agrícola e Ambiental 19: 857-864.

FLÔRES JA et al. 2017. Agronomic and qualitative traits of common bean as a function of the straw and nitrogen fertilization. Pesquisa Agropecuária Tropical 47: 195-201.

FORTE CT et al. 2018. Coberturas vegetais do solo e manejo de cultivo e suas contribuições para as culturas agrícolas. Revista Brasileira de Ciências Agrárias 13: e5501.

HIRATA ACS et al. 2009. Plantas de cobertura no controle de plantas daninhas na cultura do tomate em plantio direto. Planta Daninha 27: 465-472.

IBGE 2017. Instituto Brasileiro de Geografia e Estatística. Produção Agrícola Municipal (PAM). Disponível em https://sidra.ibge.gov.br/tabela/1612\#resultado. Acesso: 03 Abr. 2019.

KATAN J. 1981. Solar-heating (solarization) of soil for control of soil-borne pests. Annual Review of' Phytopathology 19: 211-236.

KHAN MA et al. 2012. Soil Solarization: an organic weed-management approach in cauliflower. Communications in Soil Science and Plant Analysis 43: 1847-1860.

MAGALHÃES ID et al. 2017. Physiology and grain yield of common beans under evapotranspirated water reposition levels. Irrigation \& Drainage Systems Engineering 6: 1-8.

MAIA JÚNIOR SO et al. 2018. Soil management and mulching for weed control in cowpea. Pesquisa Agropecuária Tropical 48: 453-460.

MARTINS D et al. 2016. Coberturas mortas de inverno e controle químico sobre plantas daninhas na cultura do milho. Revista Ciência Agronômica 47: 649-657.

MESCHEDE DK et al. 2007. Avaliação de diferentes coberturas na supressão de plantas daninhas no cerrado. Planta Daninha 25: 465-471.

MONQUERO PA et al. 2009. Efeito de adubos verdes na supressão de espécies de plantas daninhas. Planta Daninha 27: 85-95.

OLIVEIRA FS et al. 2018. Competition between cowpea and weeds for water: effect on plants growth. Revista Brasileira de Ciências Agrárias 13: e5507.

OSIPITAN OA. 2017. Weed interference and control in cowpea production: A review. Journal of Agricultural Science 9: 11-20.

PESSÔA UCM et al. 2017. Desempenho fisiológico e crescimento do feijão-caupi, sob manejos de plantas daninhas. Revista Verde 12: 246-250.

SALGADO TP et al. 2007. Interferência das plantas daninhas no feijoeiro carioca. Planta Daninha 25: 443-448.

SANTOS HG et al. 2013. Sistema brasileiro de classificação de solos. 3.ed. Brasília: Embrapa. 353p.

SANTOS RF et al. 2014. Solarização do solo associada à aplicação de Trichoderma spp. no controle de Sclerotinia sclerotiorun. Revista de Ciências Agrárias 57: 322-325.

SIDDIQUI MH et al. 2018. Parthenium hysterophorus herbage mulching: a potential source of weeds control in soybean (Glycine max). Planta Daninha 36: 1-9.

SOUMYA TM et al. 2004. Effect of soil solarization on weedcount, weed dry weight and pod yield of groundnut. Karnataka Journal of Agricultural Sciences 17: 548-550.

TEÓFILO TMS et al. 2012. Eficiência no uso da água e interferência de plantas daninhas no meloeiro cultivado nos sistemas de plantio direto e convencional. Planta Daninha 30: 547-556.

YEGANEHPOOR $\mathrm{F}$ et al. 2015. Effects of cover crops and weed management on corn yield. Journal of the Saudi Society of Agricultural Sciences 14: 178-181.

ZIECH ARD et al. 2014. Cultivo de alface em diferentes manejos de cobertura do solo e fontes de adubação. Revista Brasileira de Engenharia Agrícola e Ambiental 18: 948-954. 